\section{P82 Nutrition-Related Recommendations Provided by Health Care Providers Following Hypertension Diagnosis: Findings from the 2015 Kenya STEPS-Survey}

Teresia Mbogori,PhD, RDN, tnmbogori@bsu.edu, Ball State University, 2000 W. University Avenue, Muncie, IN 47304; Mengxi Zhang, PhD, Ball State University

Background: Hypertension (HTN) is the main modifiable risk factor in the prevention and management of cardiovascular diseases. Lifestyle modification may prevent development or reverse symptoms of HTN.

Objective: To determine the proportion of individuals diagnosed with HTN that were provided lifestyle modification advise by Health Care Providers (HCP) in Kenya.

Study Design, Setting, Participants: Secondary data analysis of cross-sectional data collected among 4500 Kenyan adults (18-69 years) participating in the 2015 Kenya STEPwise Approach to Surveillance study (STEPs).

Measurable Outcome/Analysis: Lifestyle modification advice was assessed using the question: "During any of your visits to a doctor or other health worker in the past 12 months, were you advised to do any of the following? a) Eat at least 5 servings of fruit and/or vegetables each day, b) Reduce fat in your diet, c) Start or do more physical activity, d) Maintain a healthy body weight or lose weight, e) Reduce sugary beverages in your diet." Diagnosis of HTN was determined by the response to the question, "Have you ever been told by a doctor or other health worker that you have raised blood pressure or hypertension?" Descriptive statistics and cross tabulations were used for data analysis.

Results: Almost half (49\%) of the participants had been screened for HTN with 484 (21.8\%) reporting that they were diagnosed with HTN. Of those diagnosed, 37\% were advised to increase intake fruits and vegetables; 37\%, 27\% and $25 \%$ were advised to reduce salt, fat, and sugary beverages intake respectively; and $21 \%$ and $22 \%$ were advised to start or do more physical activity, and maintain a healthy body weight or lose weight, respectively. Those with no education, low wealth status and younger were significantly $(P<.005)$ less likely to have received this advice.

Conclusions: Majority of those diagnosed with HTN had not received lifestyle modification advice from HCP despite this being a policy recommendation in Kenya. Policy makers need to work closely with HCP to develop appropriate policy implementation strategies.

Funding: None.

\section{Written Oral and Social Media Communication}

\section{P83 A Creative Approach to Developing Branding and Marketing Materials for the NC Summer Nutrition Program}

Jessica Soldavini, MPH, LDN, RD, Jessica6@live.unc.edu, No Kid Hungry NC, Center for Health Promotion and Disease Prevention, University of North Carolina at Chapel Hill, 1700 Martin Luther King Jr. Blvd, Chapel Hill, NC 27599; McCamy Holloway, MS, North Carolina Department of
Public Instruction; Tamara Baker, BA, No Kid Hungry NC, Center for Health Promotion and Disease Prevention, University of North Carolina at Chapel Hill

Objective: To support NC Summer Nutrition Program (NC SNP) sponsors and sites with marketing the program by developing statewide branding and marketing materials. Use of Theory or Research: Federal SNPs, including the Summer Food Service Program and National School Lunch Program Seamless Summer Option, provide free meals to children in low-income areas during the summer. These programs are highly underutilized and a major challenge faced by sponsors and sites is marketing and awareness of the SNP. Target Audience: 2018 and 2019 NC SNP sponsors and sites.

Program Description: In the spring of 2017, the NC Department of Public Instruction and No Kid Hungry NC held a NC SNP logo contest for high school students. A logo and mascot, a sun character named Ray, were selected from the entries. Over the course of the next year, a variety of promotional materials were developed featuring the logo and Ray including posters, postcards, banners, stickers, refrigerator magnets, yard signs, and videos. Ray was brought to life with a mascot costume and makes appearances throughout the state. Ray even has his own social media pages. The materials were made available to organizations running the SNP prior to the summer of 2018 and are promoted through trainings, events, websites, email campaigns, and social media.

Evaluation Methods: Online surveys with questions related to marketing strategies, including use of NC SNP marketing materials, were sent to NC SNP sponsors and sites in October of 2018 and 2019.

Results: The percentage of respondents using at least one type of NC SNP marketing material was 93\% for sponsors and $68 \%$ for sites in 2018 and 83\% for sponsors and $67 \%$ for sites in 2019. Sponsors and sites also gave positive feedback on the materials.

Conclusions: The statewide branding and marketing materials developed for the NC SNP were well-received by sponsors and sites, and helped them with marketing the program.

Funding: None.

\section{Nutrition Education Research Methods}

\section{P84 Perceived Healthfulness of Environment of Low-Income Communities by Community Extension Nutrition Educators}

Elder Varela, MA, University of Florida; Geoff Greene, PhD, $L D N, R D N$, University of Rhode Island; Tandalayo Kidd, $P h D, R D, L P N$, Kansas State University; Jesse Morrell, PhD, University of New Hampshire; Melissa Olfert, DPH, RDN, West Virginia University; Elizabeth Hall, MS, LDN, RDN, University of Tennessee; Kendra Kattelmann, PhD, LDN, RDN, FAND, South Dakota State University; Karla Shelnutt, PhD, RD, kpagan@ufl.edu, University of Florida, 3028 McCarty Hall D, Gainesville, FL, 32611

Continued on page S56 